\title{
ТЕОРІЯ І ПРАКТИКА НАВЧАННЯ УСНОМУ ПЕРЕКЛАДУ
}

\section{Ільчук Т. В.}

\section{ВСТУП}

3 появою різних націй та мов переклад як своєрідний посередник звузив існуючий пробіл між людьми та зблизив їх з різних аспектів, особливо в культурних та комерційних відносинах. Хоча видається, що усний переклад спочатку використовувався через відсутність відповідних документів у перекладознавчому дослідженні, він має давнішу історію. Однак після 1950-х років усний переклад, як нова концепція перекладу, був визначений такими вченими, як Герман ${ }^{1}{ }^{\mathrm{T}}$ Вермер $^{2}$. Згодом, через все більшу увагу до галузі усного перекладу, було введено кілька класифікацій цього поняття відповідно до часу, місця i типу використовуваного перекладу, як одночасного, так і послідовного.

Незалежно від загальної схожості двох названих відомих типів перекладу вони суттєво відрізняються під час виконання. Наприклад, хоча голосова пауза відіграє ключову роль у послідовному перекладі, паузи немає під час синхронного типу, це означає, що процеси аудіювання та говоріння відбуваються одночасно. Крім того, необхідність використання спеціальних інструментів, таких як електронні пристрої та кабінки, можна назвати як суттєві відмінності синхронного перекладу. 3 іншого боку, продуктивність перекладачів залежить від деяких основних навичок, зокрема розуміння, слухання, володіння мовою та вміння вести конспекти, яких слід навчати на курсах перекладу.

За словами С. Чена ${ }^{3}$, спочатку в рецептурному підході запису літератури автори здебільшого впроваджували системи та принципи ведення записів, а також всі роботи в цій сфері намагалися пояснити, як слід робити замітки з особистого досвіду письменника як професійного

1 Hermann, A. (1956/2002). Interpreting in antiquity (R. Morris, Trans). In F. Pochhacker \& M. Shlesinger (Eds.), The interpreting studies reader. London/New York: Routledge, 15-22

${ }^{2}$ Vermeer, H. J. (1992). Skizzen zu einer Geschicte der Translation. Frankfurt: Verlag fur interkulterelle Kommunication.

${ }^{3}$ Chen, S. (2016). Note taking in consecutive interpreting: A review with special focus on Chinese and English literature. The Journal of Specialised Translation, Issue26, 151-170. Retrieved from http://www.jostrans.org/ (accessed 12/06/2017). 
перекладача і як викладача-перекладача. Очевидно, що перша система прийняття нотаток була представлена Розаном у 1956 р. Потім, адаптувавши його правила, інші експерти, такі як С. Алліоні (1989) ${ }^{4}$, У. Беккер $(1972)^{5}$, А. Джіллі $(2005)^{6}$, Г. Кірхгофф $(1979)^{7}$ і Г. Матиссек $(1989)^{8}$, створили власні системи, побудовані зазвичай за системою Розана.

Застосовуючи практичні принципи конспектування, мовні експерти стикаються 3 двома проблемами. Перша - це можливість викладання систем та принципів навчання конспектування студентів, а друга - як їх навчити методично. Ця ситуація призвела до початку переходу від приписуючого до описового підходу. Тим часом було розроблено теорію індивідуальності викладання та досліджень мови, і деякі автори відкидали систематичне навчання нотування, тому що вони вважали, що нотування записів - це індивідуальна діяльність і про неї не слід думати. Однак $є$ такі дослідники, як Ільг та Ламберт ${ }^{9}$ Селесковіч та Ледерер ${ }^{10}$, які не прийняли теорію індивідуальності. Згодом, розглядаючи той факт, що якість $\epsilon$ центральним питанням викладання інтерпретації, дослідники зосередилися на взаємозв'язку між заміткою та усним перекладом.

\section{1. Теорія і практика навчання усному перекладу}

Усний переклад зазвичай визначається і сприймається як більшменш механічна діяльність, що складається з серії операцій кодування та декодування. Селескович відкидає це поширене сприйняття і описує усний переклад як складний пізнавальний процес і дуже вимогливу діяльність: «Це не усний переклад слів, це розкриття значень, що робить його явним для інших. <...> Усний переклад - це комунікація,

4 Allioni, S. (1989). Towards a grammar of consecutive interpretation. The Theoretical and Practical Aspects of Teaching Conference Interpretation. Udine : Campanotto.

${ }^{5}$ Becker, W. (1972). Notizentechnik. Germersheim, Germany : BBK.

${ }^{6}$ Gillies, A. (2005). Note taking for consecutive interpreting: A short course. Manchester. St. Jerome. Retrieved from http://books.google.com/book (accessed 10/06/2017).

${ }^{7}$ Kirchhoff, H. (1979). Die notationssprache als hilfsmittel des konferenzdolmetschers im konsekutivvorgang. Sprachtheorie und Sprachpraxis. Tübingen : Gunter Narr.

${ }^{8}$ Matyssek, H. (1989). Handbuch der notizentechnik f $\mathrm{r}$ dolmetscher. Heidelberg : Julius Groos

${ }^{9}$ Ilg, G. \& Lambert, S. (1996). Teaching consecutive interpreting. Interpreting 1(1), 69-99.

${ }^{10}$ Seleskovitch, D. \& Lederer, M. (1989/1995). A systematic approach to teaching interpretation. (J. Harmer, Trans.). Silver Spring, MD: Registry of Interpreters for the Deaf 
тобто аналіз вихідного повідомлення та перетворення повідомлення на форму, доступну слухачеві $<\ldots>^{11}$.

Процес, розбитий на три етапи, приблизно такий: а. Слухове сприйняття мовного висловлювання, яке несе сенс. Усвідомлення мови та розуміння мови повідомлення через процес аналізу. б. Негайне i навмисне відкидання формулювання та збереження ментального представлення повідомлення (поняття, ідеї тощо). с. Створення нового висловлювання на цільовій мові, яке повинно відповідати подвійній вимозі: воно повинно виражати оригінал повідомлення в повному обсязі, і воно повинно бути спрямоване на одержувача» ${ }^{12}$.

Оскільки розуміння та обробка сенсу є найважливішою фазою будьякого результату інтерпретації, навчання перекладачів повинне правильно поводитися з цим з точки зору прийомів та часу, відведеного на практику. Обробка сенсу є складною в будь-якому режимі усного перекладу, послідовному чи синхронному, через усний характер повідомлення. Одночасно це здається неможливим. Синхронний переклад, як описують цей режим Д. Селескович та М. Ледерер ${ }^{13},-$ неприродна вправа, яка дає перекладачу майже неможливу задачу відмежувати вихідну мову від цільової мови.

Будучи інтенсивно підданим дії перших слів, останні доводиться виробляти майже миттєво: у перекладача немає часу на обробку сенсу, і тому він найбільше піддається перекладу слів замість значення. На основі дослідження синхронних перекладів 3 реального життя Д. Селескович та Ледерер виділили вісім операцій, які перекладачі повинні виконувати. Ці операції можуть відбуватися як послідовно, так i синхронно в різний час виконання усного перекладу. Це: 1) «слухання; 2) розуміння мови; 3) концептуалізація (побудова когнітивної ремінісценції шляхом інтеграції послідовностей зв'язаного мовлення у до-наявні знання); 4) виголошення (те, що було збережено в предметній пам'яті); 5) ознайомлення 3 ситуацією, що підлягає перекладу; 6) перевірка аудіообладнання; 7) передача; 8) згадування конкретних слів» ${ }^{14}$.

Ми зупинимося на тому, щоб осмислити, що означає фактичну обробку значення. Усі теоретики-інтерпретатори згодні з тим, що успіх цієї операції багато в чому залежить від наявних знань - надзвичайно

${ }^{11}$ Seleskovitch, D., \& Lederer, M. (1989). Pédagogie raisonnée de l'interprétation. Collection "Traductologie" 4. Paris: Didier.

${ }^{12}$ Seleskovitch, D., (1989). The Interpreter, Paris: Didier.

${ }^{13}$ Lederer, M. (1978). Simultaneous Interpretation: Units of Meaning and Other Features in D. Gerver \& W.H. Sinaiko (eds.), New York: Plenum Press.

${ }^{14}$ Seleskovitch, D., \& Lederer, M. (1989). Pédagogie raisonnée de l'interprétation. Collection "Traductologie" 4. Paris: Didier. 
широка область, включаючи загальні знання, лінгвістичні знання та конкретні знання: про тему, яку обговорюватимуть, про конференцію / нараду, яка відбудеться, тощо. Попередні знання вважаються необхідною умовою для осмислення. «Розуміння - це те, що відбувається, коли з'являються нові інформаційні зв'язки із суміжними знаннями. Якщо таких знань немає, нову інформацію ігнорують» 15 .

Інші теоретики висловлюють ту саму думку, підкреслюючи першорядне значення підготовки до завдань 3 перекладу. «Для перекладача, процес розуміння набагато складніший. У нього немає часу користуватися словниками чи консультуватися 3 експертом. Єдиний спосіб, як перекладач може вплинути на процес розуміння, - це зробити попереджувальні дії перед повідомленням, що повідомляється, через вичерпну підготовку, як лексичну, так і концептуальну. У цьому сенс: жоден викладач 3 перекладу ніколи не може поставити достатнього акценту на питання підготовки» ${ }^{16}$.

Головна дія, яку повинен здійснити перекладач, має на меті допомогти йому передбачити сенс, тобто зрозуміти його, перш ніж це насправді виражається словами. Передчуття, як вказує Ледерер ${ }^{17}$, має два типи: передчуття, засноване на сенсі очікування, та очікування, засноване на мовному передбаченні. Перше, очевидно, пов'язане із загальними знаннями, тоді як останнє стосується суто мовних знань. Уіллс ${ }^{18}$ виділяє три типи того, що він називає сигналами очікування: контекстуальне, екстралінгвістичне (ситуаційне), контекст незалежне. Останні відображають знання стандартизованих комунікаційних процесів (від імені моєї делегації хотілося б подякувати..., а також за кліше або ідіоматичні фрази.

Контекстуальні та контекстно-незалежні підказки мають мовний характер, на відміну від екстралінгвістичного чи ситуаційного. Як «підвищення свідомості» 3 метою передчуття, Сеттон ${ }^{19}$ пропонує вправи, в яких «читаються промови чи стрічки доповідачів, прогнозованих після того, як слухачі будуть ознайомлені настільки,

${ }^{15}$ Seleskovitch, D., (1989). The Interpreter, Paris: Didier.

16 Presentacion, P. \& Martin, A. (1992). "Similarities and differences between interpreting and translation: implications for teaching" in C. Dollerup \& A.Lindegaard (eds.), Teaching Translation and Interpreting 2, Amsterdam/Philadelphia: John Benjamins Publishing Co.

${ }^{17}$ Lederer, M. (1978). Simultaneous Interpretation: Units of Meaning and Other Features in D. Gerver \& W.H. Sinaiko (eds.), New York: Plenum Press.

18 Wills, W. (1978). Syntactic Anticipation in German-English Simultaneous Interpreting in D. Gerver \& W.H. Sinaiko (eds.), New York: Plenum Press.

19 Setton, R. (1994). Experiments in the Application of Discourse Studies to Interpreting Training in C. Dollerup \& A. Lindegaard (eds.), Teaching Translation and Interpreting 2, Amsterdam/Philadelphia: John Benjamins Publishing Co. 
наскільки, як очікується, будуть знати про подію, ситуацію, гравців, місце тощо. Стрічка або динамік час від часу зупиняється, і студенти намагаються продовжити речення», i як подальший крок він пропонує вправи парафрази в реальному часі.

Труднощі обробки сенсу в інтерпретації виникають через оральний характер повідомлення, яке проголошується, на противагу письмовому тексту. У мовленні ми часто використовуємо слова та фрази, які додають мало інформації, але кажуть нам щось про ставлення мовця до своєї аудиторії та до того, що він говорить. Ми також часто вагаємось або заповнюємо прогалини вигуками, такими як «еееее» $\mathrm{i}$ «Гмммм», поки ми думаємо, що далі сказати. Ми можемо не перекласти речення і змішати його граматичну побудову з іншою. Усі ці риси зазвичай не зустрічаються в письмовій формі ${ }^{20}$.

Однак очікується, що «перекладач виголосить цілісну, цілком зрозумілу промову, бо якщо цього не зробити, його слухачі матимуть на думці, що саме перекладач $\epsilon$ некомпетентним, а не оратор» ${ }^{20}$. Справа зі значенням, якого слід шукати не лише на словах, але й поза ними, у намірі мовця, а також ненавмисних словесних та невербальних вираженнях (міміка, жестикуляція, голос тощо). Усний переклад, мабуть, значно більше стосується спілкування, ніж письмовий переклад. Що стосується викладання усного перекладу, то першим завданням, якого слід досягти, - це зробити так, щоб усний переклад студентів «поєднував» висловлювання. Зв'язок використовується тут, щоб підкреслити комунікативний спосіб реагування на висловлювання, тобто розуміння та передчуття, що Харріс ${ }^{20}$ називає комунікативним наміром оратора.

Таким чином, вправи на аудіювання, $є$ першим кроком до усного перекладу, які покликані змусити студентів визначити значення поза словами, зрозуміти інформацію після відкидання слів із висловлювання. Наступні вказівки, що даються студенту викладачемперекладачем: «Якщо ви не зможете записати всі цифри в серії чисел, не робіть цього, не турбуйтесь надмірно; Що зазвичай має значення це порядок. Якщо бухгалтер каже: доходи зросли з \$ 19732,55 до $\$ 21,033,41$ в 1980 році, ви, ймовірно, передасте його повідомлення досить добре, якщо перекладете його так: Доходи збільшилися на тисячі в минулому році» Гарріс іронічно зазначає: «Така кричуща жертва деталей була б анафемою для перекладачів». ${ }^{20}$. Гарріс, схоже, висловив найсміливіші погляди на усний переклад, підкресливши

${ }^{20}$ Harris, B. (1981). "Prolegomenon to a Study of the Differences Between Teaching Translation and Teaching Interpreting" in Cahiers de Traductologie no. 4, Editions de l'Université d'Otawa. 
контраст між усним перекладом та письмовим та яскраво комунікативним характером усного перекладу, що передбачає не тільки втрати, але також незначні зміни початкового значення.

«Висловлювання перекладача, - каже він, - не вважається самодостатнім, як, наприклад, текст перекладача. Як наслідок, упущення, неоднозначності та невиразні референти, які можуть бути нестерпними у перекладеному тексті, не тільки не викликають проблем, а може бути навіть бажаною економією в усному перекладі».

Саме функціональний підхід може пояснити такий успіх і виправдати невірність. У теорії скопоса Вермера ${ }^{21}$ - головне джерело натхнення для всіх функціоналістських теорій - переклад, включаючи інтерпретацію, вже не вважається "ipso facto", а є вірним наслідуванням вихідного тексту ${ }^{22}$.У світлі цієї теорії якість перекладу стає мірою досягнення скопосу за певних обставин. Якщо це досягає своєї мети, переклад оцінюється як оптимальний. Оптимальний переклад, таким чином, є «одним $з$ найкращих перекладів, можливо, за даних обставин, один із тих, хто найкраще реалізує мету, про яку йдеться». Вірність стає тоді питанням вибору залежно від поставленої мети або від замовленого завдання. Тому перекладач може вважати невірним вихідний текст / промову, якщо таким чином він не може досягти своєї мети, або задовольнити вимоги клієнта.

Крім того, законна мета усного перекладу не може бути вірним наслідуванням оригіналу. Перекладач іноді змушений змінювати оригінальну промову, щоб зробити іiі більш комунікативно ефективною, більш придатною до очікування слухачів, і останнє, але не менш важливе, лінгвістично сформульованою краще, ніж оригінал. Перекладач робить це для вигоди спікерів та/або клієнтів. Анекдот, найімовірніше, поширюється перекладачами як помста мовцям за їх презумпційне невігластво, здається, видає саму суть маніпулятивного перекладу. Доповідач скаржиться: «Це не те, що я сказав», а перекладач відповідає: «Але це ви повинні сказати» ${ }^{23}$.

Мета перекладача, очевидно, не в тому, щоб маніпулювати, а видавати текст мовою, яка ефективно підходить під комунікацію відповідної ситуації. I якщо цю мету можна було б досягти вірним перекладом, то тим краще. Від перекладача не слід очікувати, що він

21 Vermeer, H.J. (1989). Skopos and Commission in Translation Action in A. Chesterman, (ed.), Readings in Translation Theory, Helsinki: Oy Finn Lectura Ab).

22 Venuti, L. (2000). The Translation Studies Reader. London \&New York: Routledge.

${ }^{23}$ Bowen, M. (1994). "Interpreting Studies and the History of the Profession" in C. Dollerup \& A. Lindegaard (eds.), Teaching Translation and Interpreting 2, Amsterdam/ Philadelphia: John Benjamins Publishing Co. 
перекладатиме виразно, відповідно до швидкості мовця, яка в усному перекладі в 30 разів перевищує швидкість написаного тексту. Прийнятним / оптимальним перекладом у такому разі було б одне передання лише референтного значення.

Незалежно від того, наскільки суттєво різняться перекладачі та теоретики інтерпретації в поглядах на усний переклад, вони всі повністю погодяться з однією простою істиною: усний переклад - це надзвичайно напружене заняття. Д. Гіл ${ }^{24}$ сприймає інтерпретаційну виставу як функцію здатності перекладача керувати декількома видами зусиль чи стресів, а саме розумінням, дією та пам'яттю. Питання полягає в тому, що міг би зробити перекладач, щоб принаймні зменшити строк розуміння та врятувати частину «психічної» енергії, необхідної для усного перекладу, яка доступна лише 3 обмеженим постачанням.

Відповіддю може бути: отримати деяку підтримку з боку оратора, даючи йому знати про ті самі основні риси усного перекладу. Таким чином, доповідач повинен знати, що: А. Усний переклад не $є$ операцією декодування - кодування. В. Усний переклад - це акт комунікації та / або послуга. С. Не існує такого поняття, як вірний переклад. Підготовка перекладачів - це дуже тонка проблема i дуже складна, якщо не неможлива задача. Як перекладач може «реформувати» особистості, які більш-менш твердо «сформовані»? Н. Крім питання про «его» доповідачів, на міжнародних зустрічах зазвичай присутні освічені особи з науковими званнями та високим статусом. Отже, проблема $\epsilon$ в можливості фактичних контактів між доповідачами та перекладачами.

Отже, навчання перекладачів вимагає багато тактовності, великої сили переконання та багатьох інших комунікативних і педагогічних навичок, які перекладачі повинні набути під час власної підготовки. $€$ різниця між внутрішніми та вільними перекладачами. Перші мають перевагу щоденних професійних та соціальних контактів зі своїми доповідачами, що може бути перетворено на «навчальні» можливості. Останні можуть розраховувати лише на великі інструктажі із спікерами та / або клієнтами. Вони можуть звернутися до Міжнародної асоціації перекладачів, яка відповідає за захист перекладачів проти доповідачів та клієнтів. Вони встановлюють власні стандарти для усних перекладів конференцій, які повідомляються учасникам під час підготовчого етапу і які повинні мати силу джентльменських угод.

${ }^{24}$ Gile, D. (1995). Basic Concepts and Models for Interpreting and Translation Training, Amsterdam/Philadelphia: John Benjamins Publishing Co. 


\section{2. Когнітивне навантаження}

\section{під час навчання синхронному перекладу}

Багатовимірність когнітивного навантаження ускладнюе визначення: 3 одного боку, ця конструкція являє собою навантаження, накладене на виконавця особливе завдання ${ }^{25}$, 3 іншого боку, являє собою сприйняті зусилля, вкладені виконавцем під час виконання цього завдання ${ }^{26}$. Для цього аналізу когнітивне навантаження буде визначено як обсяг дієздатності, яка займає виконання пізнавального завдання у системі 3 обмеженою ${ }^{27}$. Паас ${ }^{28}$, Скултес і Джеймсон ${ }^{29}$ описують дискретні категорії методів оцінки когнітивного навантаження, все 3 відповідними перевагами та недоліками: суб'єктивні методи, методи виконання та психофізіологічні методи.

Аналітичні методи намагаються оцінити когнітивне навантаження, спираючись на суб'єктивні дані, часто отримані за допомогою експертної думки, та аналітичні дані, які генеруються за допомогою математичних моделей або аналізу завдань. Перевага такого підходу полягає в тому, що перехресний підрахунок суб'єктивних та аналітичних даних може бути сприйнятим на чисто теоретичному рівні, таким чином уникаючи іноді громіздкого емпіричного тестування; головний його недолік полягає в тому, що він покладається виключно на попередні знання обох про завдання та про предмети, і тому він не може врахувати індивідуальні відмінності в роботі.

Суб'єктивні методи використовують дані самозвіту як засіб кількісної оцінки явищ, які сприймаються як важкі або неможливі для об'єктивної оцінки. Дані генеруються за допомогою самоаналізу, а також ретроспективи та паралельної вербалізації і відображаються в таких показниках, як рейтингові шкали. Перевага цих методів перед аналітичними методами полягає в тому, що вони передбачають виконання завдань тих, хто, як було показано, здатні оцінити свою

25 Paas, Fred G.W.C., and Jeroen J.G. Merrienboer. 1993. "!e E4ciency of Instructional Conditions: An Approach to Combine Mental E"ort and Performance Measures." Human Factors 35: 737-743.

${ }^{26}$ Yin, Bo, Fang Chen, Natalie Ruiz, and Eliathamby Ambikairajah. 2008. "SpeechBased Cognitive Load Monitoring System." Proceedings of the IEEE International Conference on Acoustics, Speech and Signal Processing, 2041-2044. Las Vegas, Nevada.

${ }^{27}$ Miller, George A. 1956. "!e Magical Number Seven, Plus or Minus Two: Some Limits on our Capacity for Processing Information." Psychological Review 63: 81-97.

${ }^{28}$ Paas, Fred G.W.C., Juhani E. Tuovinen, Huib K. Tabbers, and Pascal W.M. van Gerven. 2003."Cognitive Load Measurement as a Means to Advance Cognitive Load !eory." Educational Psychologist 38 (1): 63-71.

${ }^{29}$ Schultheis, Holger, and Anthony Jameson. 2004. "Assessing Cognitive Load in Adaptive Hypermedia Systems: Physiological and Behavioral Methods." In Adaptive Hypermedia and Adaptive Web-Based Systems: Proceedings of AH 2004, ed. by Wolfgang Nejdl and Paul De Bra, 225-234. Berlin: Springer. 
ефективність у психічному навантаженні. Недолік - можливе забруднення даних за допомогою ефектів пам'яті та свідомості, за умови, що реакція зазвичай йде із затримкою в часі.

За винятком паралельної вербалізації (тобто думок вголос), самооцінка та оцінка відбувається після виконання завдання. Методи виконання зазвичай включають одночасне виконання завдання та другорядне завдання 3 метою визначення ступеня, в якій останнє впливає на попереднє $\epsilon^{30}$. Перевага цих методів полягає в тому, що вони дозволяють вивчати завдання без необхідності їх декомпозиції. Основним недоліком $\epsilon$ те, що неконтрольовані процеси можуть переплутати причинно-наслідкові зв'язки, зв'язок між двома завданнями.

Психофізіологічні методи, нарешті, оцінюють відомі фізіологічні процеси зі змінами когнітивного навантаження. При цьому вони забезпечують більш прямі процеси, враховуючи, що ці фізіологічні відповіді не підлягають добровільному контролю, більш об’єктивній мірі когнітивного навантаження. Недоліком цих методів $є$ їхня складність; вони можуть бути інвазивними (різною мірою) і тому можуть заважати із самим завданням. Далі йде спроба проілюструвати за допомогою кількох прикладів, як ці методи були використані для визначення та кількісної оцінки явищ пізнавального навантаження в синхронному перекладі. Пізнавальне навантаження в дослідженні синхронного перекладу: Аналітичні методи - серед найбільш відомих аналітичних підходів до розуміння когнітивного навантаження - усний переклад моделей зусиль Гіла ${ }^{31}$. Основою цього $є$ «Концептуальні рамки» ${ }^{32}$, схожі на сингл Канемана ${ }^{33}$, теорія ресурсів, яка постулює існування єдиного пулу завершеної обробки здатності підживлювати всі пізнавальні завдання.

В узагальненні складніших операцій під керівництвом чотирьох зусиль, тобто слухання та аналіз, виробництво, пам'ять і координації, Гіл пропонує просту архітектуру для опису кількості зусиль, вкладених в одночасне виконання цих операцій: вхід «Я» до загальної суми вкладеного зусилля як звернення цієї концептуальної основи - iii вражаюча простота. Зменшення складних завдань синхронного перекладу нескладної математичної формули (яку, як зазначає автор, не

${ }^{30}$ Haapalainen, Eija, SeungJun Kim, Jodi F. Forlizzi, and Anind K. Dey. 2010. "Psycho-Physiological Measures for Assessing Cognitive Load." In Proceedings of the 12th International Conference on Ubiquitous Computing, 301-310. Copenhagen.

${ }^{31}$ Gile, Daniel. 1995. Regards sur la recherche en interprétation de conférence. Lille: Presses universitaires de Lille.

${ }^{32}$ Gile, Daniel. 2008. "Local Cognitive Load in Simultaneous Interpreting and its Implications for Empirical Research." Forum 6 (2): 59-77.

${ }^{33}$ Kahneman, Daniel. 1973. Attention and E"ort. Englewood Cli's, NJ : Prentice-Hall 
слід розуміти як просту арифметичну суму) - помітний подвиг. Один із прикладів, який надає Гіл, ілюструє процес вимоги до можливостей, пов'язаних 3 синхронним перекладом речення. Збільшення щільності інформації (тобто розділ курсивом) спричиняє ефект стукоту і зрештою призводить до того, що навантаження експортується на наступну стадію обробки. Однак основна сила цієї моделі, тобто іiі здатність охоплювати складне завдання синхронного перекладу та подання простого та стислого опису його сукупності - когнітивних вимог, $\epsilon$ потенційною слабкістю щодо ії застосування поза його межами

Пізнавальне навантаження під час синхронного перекладу: заходи та методи розумових зусиль, необхідних для виконання задачі синхронного перекладу або породженого ним когнітивного навантаження викликало інтерес багатьох дослідників. Сьогодні, однак, мало домовленостей щодо найбільш підходящого методу для вимірювання цього явища.

Основна увага буде приділена психофізіологічному методу, який $\epsilon$ одним 3 найбільш перспективних підходів до об'єктивного вимірювання пізнавального навантаження під час синхронного перекладу в режимі реального часу. Серед науковців-перекладачів перелік тих, хто вважає одночасним інтер-передбачення пізнавальної діяльності (наприклад, Гіл ${ }^{34}$; Хона ${ }^{35}$, Масаро і Шлезінгер ${ }^{36}$, МосеМерсер $^{37}$, Де Грут) $)^{38}$, здається, виходить за межі твердження тих, хто вважає такі твердження нічим іншим, як «примітивами чи кліше» ${ }^{39}$. Дійсно, Сеттон стверджує, що паралельні підзадачі під час синхронного перекладу може бути виконано «зручно», якщо всі вони

${ }^{34}$ Gile, Daniel. 1995. Regards sur la recherche en interprétation de conférence. Lille: Presses universitaires de Lille.

${ }^{35}$ Hyönä, Jukka, Jorma Tommola, and Anna-Mari Alaja. 1995. "Pupil Dilation as a Measure of Processing Load in Simultaneous Interpreting and Other Language Tasks." !e Quarterly Journal of Experimental Psychology 48A (3): 598-612.

${ }^{36}$ Massaro, Dominic W., and Miriam Shlesinger. 1997. "Information Processing and a Computational Approach to the Study of Simultaneous Interpretation." Interpreting 1 (1/2): 13-53.

${ }^{37}$ Moser-Mercer, Barbara. 1997. "Beyond Curiosity. Can Interpreting Research Meet the Challenge?" In Cognitive Processes in Translation and Interpreting, ed. by Joseph H. Danks, Stephen B. Fountain, Michael K. McBeath, and Gregory M. Shreve, 176-195. !ousand Oaks, London, New Delhi: Sage Publications.

${ }^{38}$ De Groot, Annette M.B. 2000. "A Complex-skill Approach to Translation and Interpreting." In Tapping and Mapping the Processes of Translation and Interpreting, ed. by Sonja TirkkonenCondit and Riitta Jääskeläinen, 53-68. Amsterdam: John Benjamins.

39 Setton, Robin. 2003. "Models of the Interpreting Process." In Avances en la investigación sobre la interpretación, ed. by Angela Collados Aís and José Antonio Sabio Panilla, 29-91. Granada: Editorial Comares. 
однаково представлені ${ }^{40} .3$ роками поняття когнітивного навантаження завданням з перекладу або кількістю пізнавальних зусиль, необхідних для його виконання, викликало значну зацікавленість, i до них зверталися науковці зсередини та поза парадигми, які вважають, що таке розслідування може бути дуже плідним

Багатовимірність когнітивного навантаження ускладнює визначення. 3 одного боку, ця конструкція являє собою навантаження, накладене на виконавця особливе завдання ${ }^{41}$, 3 іншого боку, воно являє собою сприйняті зусилля, вкладені виконавцем під час виконання цього завдання ${ }^{42}$. Для цього когнітивне навантаження буде визначено як обсяг дієздатності, яке виконання пізнавального завдання займає у спадок-системи з обмеженою ємністю ${ }^{43}$.

Аналітичні методи намагаються оцінити когнітивне навантаження, спираючись на суб'єктивні дані, часто отримані за допомогою експертної думки, та аналітичні дані, які часто генеруються за допомогою математичних моделей або аналізу завдань. Суб'єктивні методи використовують дані самозвіту як засіб кількісної оцінки явищ, які сприймаються як важкі або неможливі для об’єктивної оцінки. Дані генеруються за допомогою самоаналізу, а також ретроспективи та паралельної вербалізації і відображається в таких показниках, як рейтингові шкали.

Емпіричні висновки не надають однозначної підтримки Канеману ${ }^{44}$ про теорію єдиних ресурсів. Навпаки, вони виявляють, що структурно подібні завдання заважають більше один одному, ніж структурно несхожі $^{45}$. Огляд недавньої літератури свідчить про те, що на відміну від аналітичних методів типові методи, здається, не застосовуються широко для оцінки когнітивного навантаження під час інтерпретації дослідження. Можливо, це пояснюється двома причинами. 3 одного боку, мало погоджуватися щодо надійності самозвітів про когнітивне

${ }^{40}$ Setton, Robin. 2001. "Translation Studies and Cognitive Science: Do we Need each other?" CTIS Occasional Papers 1: 113-126.

41 Paas, Fred G.W.C., and Jeroen J.G. Merrienboer. 1993. "!e E4ciency of Instructional Conditions: An Approach to Combine Mental E"ort and Performance Measures." Human Factors 35: 737-743.

${ }^{42}$ Yin, Bo, Fang Chen, Natalie Ruiz, and Eliathamby Ambikairajah. 2008. "SpeechBased Cognitive Load Monitoring System." Proceedings of the IEEE International Conference on Acoustics, Speech and Signal Processing, 2041-2044. Las Vegas, Nevada.

${ }^{43}$ Miller, George A. 1956. "!e Magical Number Seven, Plus or Minus Two: Some Limits on our Capacity for Processing Information.” Psychological Review 63: 81-97.

${ }^{44}$ Kahneman, Daniel. 1973. Attention and E"ort. Englewood Cli"s, NJ: Prentice-Hall.

${ }^{45}$ Wickens, Christopher D. 2002. "Multiple Resources and Performance Prediction." !eoretical Issues in Ergonomics Science 3 (2): 159-177. 
навантаження. Хоча деякі (наприклад, Гофер і Браун ${ }^{46}$, Паас та інші ${ }^{47}$ ) визнали їх відносно надійними, інші (наприклад, Мітал i Говіндаражу ${ }^{48}$ ) виявили докази протилежного. 3 іншого боку, визнається, що лише паралельна вербалізація може точно відображати психічний статус учасників ${ }^{49}$, а також постмобільна вербалізація після довгих завдань може призвести до неповного опису ${ }^{50}$ та викривлення.

Передбачаючи дослідження, Іванова ${ }^{51}$ пропонує використовувати стенограми виводу перекладачів як підказки пошуку під час постмобільних вербалізацій. Такий підхід заохочує учасників швидше згадувати, ніж реконструювати пізнавальні процеси, але не вирішує проблему тісної взаємодії учасника та експериментатора ${ }^{52}$.

Нарешті, суб'єктивність також пробивається в наукове дослідження через фоновий підбір матеріалу для експериментальних цілей. Вибір стипендіатів та вихідних матеріалів для експериментів 3 синхронного перекладу і пов'язані з ними завдання (тобто затінення, переклад зоровий, синхронний переклад 3 текстом тощо) на основі суб'єктивної оцінки складності. Читачам кажуть, наприклад, що матеріали, які вилучились, мають приблизно однакову складність ${ }^{53}$ i, таким чином, залишається довіряти дослідникам (інтерпретаторам) у їх суб'єктивній оцінці.

Для дослідження когнітивного навантаження одночасно застосовуються різні методи перекладу. Хоча кожен із підходів має свої унікальні переваги та недоліки, цей аналіз пропонує використання спостережень за студентами, як способу спостереження об'єктивніше, скільки пізнавального навантаження створюється під час перекладу в

${ }^{46}$ Gopher, Daniel, and Rolf Braune. 1984. "On the Psychophysics of Workload: Why Bother with Subjective Measures?" Human Factors 26: 519-532.

${ }^{47}$ Paas, Fred G.W.C., Juhani E. Tuovinen, Huib K. Tabbers, and Pascal W.M. van Gerven. 2003. "Cognitive Load Measurement as a Means to Advance Cognitive Load !eory.” Educational Psychologist 38 (1): 63-71.

${ }^{48}$ Mital, Anil, and Majorkumar Govindaraju. 1999. "Is It Possible to Have a Single Measure for all Work?" International Journal of Industrial Engineering !eory 6: 190-195.

49 Bernardini, Silvia. 2001. "!ink-Aloud Protocols in Translation Research: Achievements, Limits, Future Prospects." Target 13 (2): 214-263.

${ }^{50}$ Ericsson, Anders K., and Herbert A. Simon. 1984. Protocol Analysis: Verbal Reports as Data. Cambridge, MA: Bradford Books/MIT Press.

${ }^{51}$ Ivanova, Adelina. 2000. "!e Use of Retrospection in Research on Simultaneous Interpreting." In Tapping and Mapping the Processes of Translation and Interpreting, ed. by Sonja TirkkonenCondit and Riitta Jääskeläinen, 27-52. Amsterdam: John Benjamins.

52 Bernardini, Silvia. 2001. "!ink-Aloud Protocols in Translation Research: Achievements, Limits, Future Prospects.” Target 13 (2): 214-263.

53 Moser-Mercer, Barbara, Ulrich Frauenfelder, Beatriz Casado, and Alexander Künzli. 2000. "Searching to De\#ne Expertise in Interpreting." In Language Processing and Simultaneous Interpreting, ed. by Birgitta Englund Dimitrova and Kenneth Hyltenstam, 107-132. Amsterdam: John Benjamins. 
процесі. Навіть цей захід зараз застосовується 3 моменту ще невирішених викликів. Насправді, здавалося б, поки надійний засіб для оцінки локального пізнавального навантаження на рівні речення або поза цим методом повинен бути визначений для кількісної оцінки середнього когнітивного навантаження на довгі подразники. Хоча багатозначне відображення все ще не дозволяє нам віднести їх виміряне навантаження на окремі складники завдання. Так само, як і $з$ іншими обмеженнями, визначеними в цьому огляді, вони не повинні припускати, що метод $є$ непридатним або недійсним.

\section{ВИСНОВКИ}

Як ми намагалися запропонувати в цій роботі, тлумачення методів навчання надихається та породжується теорією, теорія базується на емпіричних доказах. Теорію та практику, формалізацію та інтуїцію навряд чи можна розділити в такій складній діяльності, як усний переклад.

Це дослідження прагнуло дослідити якісні відмінності між студентом та професійним перекладачем у швидкості перекладу, часі передачі інформації, точності та якості мови перекладу через міжпредметну мінливість. У цьому напряму роботи більшість перекладачів-студентів порівняно 3 професійними перекладачами, 3 точки зору швидкості читання, точності та якості мови перекладу мають куди рухатись у вдосконаленні своїх навичок. I викладачі, і перекладачі стають на бік студентів, щоб передати свої найкращі уміння.

За словами Бейкера та Маєра ${ }^{54}$, заняття в аудиторії повинні забезпечити можливості для залучення студентів до таких питань, як концептуальні інструменти, які їм потрібно критично обгрунтувати, наслідки будь-якого рішення, низку потенційних стратегій, які можуть бути використані для вирішення етично складних або компрометуючих ситуацій. I, нарешті, педагогам потрібно розробити набір педагогічних інструментів, які можна використовувати для створення середовища, в якому студенти можуть надавати етичні рішення, відтворювати наслідки таких рішень та вчитись на цьому досвіді.

У дослідженні висвітлені основні питання, 3 якими зіштовхуються викладачі під час навчання усному перекладу. Це дослідження може підтвердити, що застосування різних методів та викладацьких підходів може бути успішно інтегроване з курсами перекладу як необхідна умова можливих методів синхронного перекладу та послідовного перекладу. Усвідомлення конкретних прийомів усного перекладу прокладає спосіб навчання для студентів та встановлення для них

${ }^{54}$ Baker, M. and Maier, C. (2011). Ethics in interpreter and translator training. The interpreter and translator trainers. 5(1), 1-14. 
цілей, які відрізняють ці курси від інших подібних курсів. Ця робота також дає викладачам своєрідну основу для викладання послідовного та синхронного перекладу. Результати цього дослідження також можуть бути корисними для інших подібних контекстів у навчанні перекладу.

\section{АНОТАЦІЯ}

Переклад - це доручене завдання, метою якого $є$ встановлення можливості спілкування. Сенс, який має бути переданий, тобто оптимальний переклад, розглядається як функція ситуації спілкування, яку слід шукати поза межами слова, у «девербалізованому» стані. Усний переклад студентів повинен викладатись як той, що передбачає певну невірність або маніпуляцію, і однією $з$ важливих вимог до перекладу $€$ підготовка лекторів до певної відповідальності за виконання усного перекладу. Увага - це одна 3 найважливіших навичок, яка використовується для полегшення процесу усного перекладу та різних аспектів майстерності, досліджених в історії інтерпретації. Це дослідження ознайомлює 3 твердженнями про переклад викладачів та студентів 3 метою виявлення слабких сторін викладання. Мета цього дослідження - показати різні методи та підходи до навчання усному перекладу. Результати дослідження чітко вказують на те, що викладання курсів перекладу некваліфікованими викладачами частіше за все під час використання навчальних програм для перекладу з відповідних курсів охоплюють не всі аспекти проблеми та повинні відповідати майбутнім потребам студентів у ролі професійних перекладачів.

\section{ЛITЕРАТУРА}

1. Allioni, S. (1989). Towards a grammar of consecutive interpretation. The Theoretical and Practical Aspects of Teaching Conference Interpretation. Udine: Campanotto.

2. Baker, M. and Maier, C. (2011). Ethics in interpreter and translator training. The interpreter and translator trainers. 5(1), 1-14.

3. Becker, W. (1972). Notizentechnik. Germersheim, Germany : BBK.

4. Bernardini, Silvia. 2001. "link-Aloud Protocols in Translation Research: Achievements, Limits, Future Prospects.” Target 13 (2): 214-263.

5. Bowen, M. (1994). "Interpreting Studies and the History of the Profession" in C. Dollerup \& A. Lindegaard (eds.), Teaching Translation and Interpreting 2,Amsterdam/Philadelphia: John Benjamins Publishing Co.

6. Chen, S. (2016). Note taking in consecutive interpreting: A review with special focus on Chinese and English literature. The Journal of Specialised Translation, Issue26, 151-170. Retrieved from http://www.jostrans.org/ (accessed 12/06/2017). 
7. De Groot, Annette M.B. 2000. "A Complex-skill Approach to Translation and Interpreting." In Tapping and Mapping the Processes of Translation and Interpreting, ed. by Sonja TirkkonenCondit and Riitta Jääskeläinen, 53-68. Amsterdam : John Benjamins.

8. Ericsson, Anders K., and Herbert A. Simon. 1984. Protocol Analysis: Verbal Reports as Data. Cambridge, MA : Bradford Books/MIT Press.

9. Gile, D. (1995). Basic Concepts and Models for Interpreting and Translation Training, Amsterdam/Philadelphia: John Benjamins Publishing Co.

10. Gile, Daniel. 1995. Regards sur la recherche en interprétation de conférence. Lille: Presses universitaires de Lille.

11. Gile, Daniel. 2008. "Local Cognitive Load in Simultaneous Interpreting and its Implications for Empirical Research." Forum 6 (2) : 59-77.

12. Gillies, A. (2005). Note taking for consecutive interpreting: A short course. Manchester. St. Jerome. Retrieved from http://books.google.com/book (accessed 10/06/2017).

13. Gopher, Daniel, and Rolf Braune. 1984. "On the Psychophysics of Workload: Why Bother with Subjective Measures?" Human Factors 26: 519-532.

14. Haapalainen, Eija, SeungJun Kim, Jodi F. Forlizzi, and Anind K. Dey. 2010. "Psycho-Physiological Measures for Assessing Cognitive Load." In Proceedings of the 12th International Conference on Ubiquitous Computing, 301-310. Copenhagen.

15. Harris, B. (1981). "Prolegomenon to a Study of the Differences Between Teaching Translation and Teaching Interpreting" in Cahiers de Traductologie no. 4, Editions de l'Université d'Otawa.

16. Hermann, A. (1956/2002). Interpreting in antiquity (R. Morris, Trans). In F. Pochhacker \& M. Shlesinger (Eds.), The interpreting studies reader. London/New York : Routledge, 15-22

17. Hyönä, Jukka, Jorma Tommola, and Anna-Mari Alaja. 1995. "Pupil Dilation as a Measure of Processing Load in Simultaneous Interpreting and Other Language Tasks." !e Quarterly Journal of Experimental Psychology 48A (3) : 598-612.

18. Ilg, G. \& Lambert, S. (1996). Teaching consecutive interpreting. Interpreting 1(1), 69-99.

19. Ivanova, Adelina. 2000. "!e Use of Retrospection in Research on Simultaneous Interpreting." In Tapping and Mapping the Processes of Translation and Interpreting, ed. by Sonja TirkkonenCondit and Riitta Jääskeläinen, 27-52. Amsterdam : John Benjamins.

20. Kahneman, Daniel. 1973. Attention and E'ort. Englewood Cli's, NJ: Prentice-Hall

21. Kirchhoff, H. (1979). Die notationssprache als hilfsmittel des konferenzdolmetschers im konsekutivvorgang. Sprachtheorie und Sprachpraxis. Tübingen : Gunter Narr. 
22. Lederer, M. (1978). Simultaneous Interpretation: Units of Meaning and Other Features in D. Gerver \& W.H. Sinaiko (eds.), New York : Plenum Press.

23. Massaro, Dominic W., and Miriam Shlesinger. 1997. "Information Processing and a Computational Approach to the Study of Simultaneous Interpretation." Interpreting 1 (1/2): 13-53.

24. Matyssek, H. (1989). Handbuch der notizentechnik f r dolmetscher. Heidelberg : Julius Groos

25. Miller, George A. 1956. "!e Magical Number Seven, Plus or Minus Two: Some Limits on our Capacity for Processing Information." Psychological Review 63: 81-97.

26. Mital, Anil, and Majorkumar Govindaraju. 1999. "Is It Possible to Have a Single Measure for all Work?" International Journal of Industrial Engineering !eory $6: 190-195$.

27. Moser-Mercer, Barbara, Ulrich Frauenfelder, Beatriz Casado, and Alexander Künzli. 2000. "Searching to De\#ne Expertise in Interpreting." In Language Processing and Simultaneous Interpreting, ed. by Birgitta Englund Dimitrova and Kenneth Hyltenstam, 107-132. Amsterdam : John Benjamins.

28. Moser-Mercer, Barbara. 1997. "Beyond Curiosity. Can Interpreting Research Meet the Challenge?" In Cognitive Processes in Translation and Interpreting, ed. by Joseph H. Danks,Stephen B. Fountain, Michael K. McBeath, and Gregory M. Shreve, 176-195. ousand Oaks, London, New Delhi : Sage Publications.

29. Paas, Fred G.W.C., and Jeroen J.G. Merrienboer. 1993. "!e E4ciency of Instructional Conditions: An Approach to Combine Mental E'ort and Performance Measures". Human Factors 35 : 737-743.

30. Paas, Fred G.W.C., Juhani E. Tuovinen, Huib K. Tabbers, and Pascal W.M. van Gerven. 2003."Cognitive Load Measurement as a Means to Advance Cognitive Load !eory". Educational Psychologist 38 (1): 63-71.

31. Presentacion, P. \& Martin, A. (1992). "Similarities and differences between interpreting and translation: implications for teaching" in C. Dollerup \& A.Lindegaard (eds.), Teaching Translation and Interpreting 2, Amsterdam/Philadelphia : John Benjamins Publishing Co.

32. Schultheis, Holger, and Anthony Jameson. 2004. "Assessing Cognitive Load in Adaptive Hypermedia Systems: Physiological and Behavioral Methods." In Adaptive Hypermedia and Adaptive Web-Based Systems: Proceedings of AH 2004, ed. by Wolfgang Nejdl and Paul De Bra, 225-234. Berlin : Springer.

33. Seleskovitch, D. \& Lederer, M. (1989/1995). A systematic approach to teaching interpretation. (J. Harmer, Trans.). Silver Spring, MD: Registry of Interpreters for the Deaf.

34. Seleskovitch, D., \& Lederer, M. (1989). Pédagogie raisonnée de l'interprétation. Collection "Traductologie" 4. Paris : Didier. 
35. Seleskovitch, D., (1989). The Interpreter, Paris : Didier.

36. Setton, R. (1994). Experiments in the Application of Discourse Studies to Interpreting Training in C. Dollerup \& A. Lindegaard (eds.), Teaching Translation and Interpreting 2, Amsterdam/Philadelphia : John Benjamins Publishing Co.

37. Setton, Robin. 2001. "Translation Studies and Cognitive Science: Do we Need each other?" CTIS Occasional Papers 1: 113-126.

38. Setton, Robin. 2003. "Models of the Interpreting Process." In Avances en la investigación sobre la interpretación, ed. by Angela Collados Aís and José Antonio Sabio Panilla, 29-91. Granada : Editorial Comares.

39. Venuti, L. (2000). The Translation Studies Reader. London \&New York : Routledge.

40. Vermeer, H.J. (1992). Skizzen zu einer Geschicte der Translation. Frankfurt : Verlag fur interkulterelle Kommunication.

41. Vermeer, H.J. (1989). Skopos and Commission in Translation Action in A. Chesterman, (ed.), Readings in Translation Theory, Helsinki : Oy Finn Lectura $\mathrm{Ab}$ ).

42. Wickens, Christopher D. 2002. "Multiple Resources and Performance Prediction". Teoretical Issues in Ergonomics Science 3 (2) : 159-177.

43. Wills, W. (1978). Syntactic Anticipation in German-English Simultaneous Interpreting in D. Gerver \& W.H. Sinaiko (eds.), New York : Plenum Press.

44. Yin, Bo, Fang Chen, Natalie Ruiz, and Eliathamby Ambikairajah. 2008. "Speech-Based Cognitive Load Monitoring System." Proceedings of the IEEE International Conference on Acoustics, Speech and Signal Processing, 2041-2044. Las Vegas, Nevada.

Information about the author: Ilchuk T. V.

Senior Teacher of the Department of Oriental Languages National Academy of Security Service of Ukraine 22, Mykhaylo Maksimovych Street, Kyiv, Ukraine 